\title{
Human brown fat and obesity: methodological aspects
}

\section{Wouter van Marken Lichtenbelt*}

Department of Human Biology, School for Nutrition and Toxicology and Metabolism, Maastricht University Medical Center, Maastricht, Netherlands

\section{Edited by:}

Patrick Seale, University of

Pennsylvania, USA

Reviewed by:

Timo Dirk Mueller, University of Cincinnati, USA

Maximilian Bielohuby,

Ludwig-Maximilians University,

Germany

*Correspondence:

Wouter van Marken Lichtenbelt, Department of Human Biology,

Maastricht University, P.O. box 616, $6200 \mathrm{MD}$ Maastricht, Netherlands.

e-mail:markenlichtenbelt@

maastrichtuniversity.nl

\begin{abstract}
Much is known about brown adipose tissue (BAT) in rodents. Its function is to generate heat in response to low environmental temperatures and to diet or overfeeding. The knowledge about BAT in humans is still rather limited despite the recent rediscovery of its functionality in adults. This review highlights the information available on the contribution of BAT in increasing human energy expenditure in relation to obesity. Besides that methodological aspects will be discussed that need special attention in order to unravel the heat producing capacity of human BAT, the recruitment of the tissue, and its functionality.
\end{abstract}

Keywords: brown adipose tissue, obesity, PET/CT, non-shivering thermogenesis

\section{INTRODUCTION}

In the past 3 years more than 40 reviews and commentaries on human brown adipose tissue (BAT) appeared in peer reviewed journals. This revival in the interest in BAT followed the publications on this topic in the NEJM of May 2009 (Cypess et al., 2009; van Marken Lichtenbelt et al., 2009; Virtanen et al., 2009). In the 2-years period that followed only five publications on addition al experimental studies on human BAT appeared (Saito et al., 2009; Zingaretti et al., 2009; Orava et al., 2011; Vijgen et al., 2011; Yoneshiro et al., 2011) and at least eight retrospective patient studies (Au-Yong et al., 2009; Lebron et al., 2010; Pfannenberg et al., 2010; Zukotynski et al., 2010; Gilsanz et al., 2011; Hong et al., 2011; Lee et al., 2011a; Wang et al., 2011). The somewhat misbalanced amount of reviews indicates the strong interest in human BAT by researchers and the interest sparked by the general public. Probably, this attention was already latent, fueled by numerous studies on the topic of non-shivering thermogenesis (NST) and BAT in rodents and humans in the years 1960-1985 and by the promise from animal studies that BAT can dissipate large amounts of energy as body heat at times of obesity pandemic.

The reason for the temporal disinterest in human BAT following 1985 was that some elaborate physiological studies on human BAT in those years concluded that in adults BAT was not of significant importance (Astrup et al., 1985). These studies mainly focused on perirenal BAT, which is abundant in newborns, but relatively scarce in human adults. There was a small revival in the interest in facultative diet induced thermogenesis (DIT) and BAT in humans following the paper by Stock (1999). It was not until the application of the new technique positron emission tomography - computed tomography (PET/CT) combined with a glucose tracer that it became clear that adults do have functional active BAT, but several major depots appeared to exist at other locations than thought before (Nedergaard et al., 2007).

Another important reason for the current interest in BAT physiology comes from series of interesting discoveries in the last 4 years in animal and cell biology studies. Much more is now known about the molecular mechanisms of thermogenesis, the regulation of brown fat development, its cellular lineage specification, and molecular control (for an overview see among others (Seale, 2010).

Therefore, one would expect that after the publications on BAT in 2009, it would take about 1.5 year before an explosion of publications on BAT studies in human adults would appear. However, the relative silence may be explained by the fact that setting up the mix of expertise and the right multidisciplinary laboratory facilities takes more time. Congress abstracts and proceedings indicate that at least several experimental studies are underway to be published. With respect to the reviews published, two of the most elaborate ones are from Fruhbeck et al. (2009) and Tseng et al. (2010).

In the mean time, to what extend can the expectations that were raised to combat obesity be met? In fact, the main composite question is: does human facultative and adaptive thermogenesis (DIT and cold-induced thermogenesis, CIT) have a significant contribution to our energy expenditure, is BAT involved and can these phenomena be used to fight obesity? The recent gathered knowledge with the limited numbers of studies available on the factors that influence prevalence of BAT is reviewed in Nedergaard et al. (2011). The current perspective will therefore be restricted to the (potential) contribution of BAT in increasing energy expenditure to act against obesity and to methodological aspects that need special attention in order to perform sound metabolic studies to enhance our knowledge on the functionality of human BAT.

\section{NON-SHIVERING THERMOGENESIS AND BAT NON-SHIVERING THERMOGENESIS}

Non-shivering thermogenesis is most extensively studied in rodents. The documented level of NST in rodents amounts to more than $150 \%$ percent of basal metabolic rate (BMR; Davis et al., 1960). In adult humans the NST under mild cold exposure shows 
a large individual variation and varies from 0 to $30 \%$ (Dauncey, 1981; Warwick and Busby, 1990; van Ooijen et al., 2001; Claessensvan Ooijen et al., 2006; Celi et al., 2010; Wijers et al., 2010). For a more detailed overview of these studies see van Marken Lichtenbelt and Schrauwen (2011). The maximal level of NST of humans is not known. Rodents, who are fully dependent on BAT for NST, clearly demonstrate that the capacity for NST and BAT activity depends on the level of acclimatization to cold (Golozoubova et al., 2001; Meyer et al., 2011). Heat production in BAT is by mitochondrial uncoupling and is executed by uncoupling protein-1 (UCP1). This is a BAT specific inner-membrane mitochondrial protein. Under "normal" circumstances F (0)F(1)-ATPase uses most of the energy stored in the proton gradient to produce ATP, which is the energy intermediate in the organism. UCP1 causes a reflux of protons into the mitochondrial matrix, bypassing the ATPase. Instead of ATP, heat is dissipated by the uncoupling itself but also by the other parts of the phosphorylation process (Nicholls and Locke, 1984; Klingenberg and Huang, 1999; Cannon and Nedergaard, 2004). In other words the overall cell efficiency to produce ATP drops by mitochondrial uncoupling. UCP1 is a member of a mitochondrial carrier protein family (like UCP2, UCP3). UCP1, however, is the only protein from this family that is shown to mediate NST (Nedergaard et al., 2001) in BAT, at least in rodents.

In humans the classical studies of Davis clearly show that (parallel to rodent studies) during regular cold exposure shivering decreases, while the level of CIT increases (Davis et al., 1960). This indicates that indeed NST increased in adult humans. The anatomical/histological studies by Huttunen et al. (1981) demonstrate high amounts of BAT in Finnish outdoor workers (Huttunen et al., 1981). Combining the results of these studies in humans at least suggest that with increasing NST capacity the amount of BAT increases. Contrary to rodents there are studies that indicate that in humans skeletal muscle NST by cold-induced mitochondrial uncoupling is involved (Wijers et al., 2008, 2011). It is interesting to note that with cold acclimatization, not only the capacity for NST increases, but in parallel the BMR also rises.

In conclusion, human NST can amount up to $30 \%$ of BMR, but it is possible that by means of cold acclimatization higher levels are possible. There is a large individual variation, which can in part be explained by different levels of cold acclimatization. These levels of cold acclimatization may in turn be linked to body composition (see below).

\section{BAT OR BRITE}

Adult human brown fat was anatomically described (Cramer, 1920; Heaton, 1972; Tanuma et al., 1975, 1976) many years ago, and significant amounts of BAT have for long been demonstrated in adults living in cold environments from samples obtained by necropsy (Huttunen et al., 1981). More recently, unrelated pursuits within nuclear medicine, using FDG-PET/CT scans, indicated that BAT is present and active in adult patients (Hany et al., 2002; Cohade et al., 2003; Yeung et al., 2003; Nedergaard et al., 2007), followed by experimental studies on cold activated BAT (Saito et al., 2009; van Marken Lichtenbelt et al., 2009; Virtanen et al., 2009). With a PET scan performed 45-60 min after intravenous injection of ${ }^{18} \mathrm{~F}$-2-fluoro-2-deoxyglucose (FDG), glucose uptake can be visualized. FDG is taken up via members of the sodium-independent glucose transporter family (such as GLUT1, GLUT3, and GLUT4). Therefore it provides a measure of the volume of brown fat and a measure of glucose uptake in BAT, especially so with the dynamic PET/CT scans. From these scans, however, it cannot be determined how pure (brown adipocyte density relative to white adipocytes) the BAT tissue is. Alternatively BAT perfusion has recently been measured using PET/CT in humans using labeled water $\left(\left[{ }^{15} \mathrm{O}\right] \mathrm{H}_{2} \mathrm{O}\right.$; Orava et al., 2011).

Animal and cell line studies have revealed much information on the embryonic development of BAT and skeletal muscle (Seale et al., 2008). Brown adipocytes from distinct depots and skeletal muscle cells share common precursors. Subscapular and perirenal BAT in rodents consists of almost $100 \%$ brown adipocytes. In contrast, brown-like adipocytes emerging in white adipose tissue ("BRITE-brown-in-white adipocytes") originate from other precursors, that are shared with white adipocytes (Petrovic et al., 2010). This tissue thus consists of a mixture of brown and white adipocytes. It is also possible that BRITE cells come from transdifferentiation of white adipocytes (Cinti, 2009). A very recent cell culture study provided the first evidence of inducible brown adipogenesis in humans (Lee et al., 2011b).

To address the specific origin of human brown fat cells definite anatomical, histological, and molecular measurements are needed. Some information is already available. To some extend there is a shift in the BAT depots from newborns to adults (Figure 1). Metabolic studies related to brown fat or NST in newborns are very scarce (but see for instance; Karlberg et al., 1965). However, older histological studies show that there is a large interscapular depot in newborns, resembling that of rodents, but probably more mixed with white adipocytes (Merklin, 1974). The most pure BAT depots in newborns are located posterior cervical, perirenal, and suprailiac. Most of the interscapular and suprailiac depots disappear during growth. Also the perirenal BAT is much more abundant in newborns than in adults. In older children at least from the age of 9 year and in adult humans the most important sites are supraclavicular, axillary, and paravertebral (Hong et al., 2011; van Marken Lichtenbelt and Schrauwen, 2011). Although these sites are also reported in newborns it is possible that in adults much of these tissues consist of later recruited brown(like) adipocytes. It therefore is possible that these sites in fact are BRITE cell depots. Indeed, all histological observations of BAT in humans show that brown adipocytes are mixed with white adipocytes (Heaton, 1972; Cypess et al., 2009; van Marken Lichtenbelt et al., 2009; Zingaretti et al., 2009). Even in the major supraclavicular depots the tissue consists of a mixture of brown and white cells (Virtanen et al., 2009). The cell composition of human BAT and whether the distinction between BAT and BRITE has functional consequences remains to be investigated. Nevertheless, it is likely that the density of the brown fat (like) adipocytes determines the mass-specific metabolic capacity of the tissue.

\section{BAT AND NST}

Rodents fully depend on BAT with respect to NST (Cannon and Nedergaard, 2004). The quantitative contribution of BAT to NST in humans still needs to be elucidated. Up to this day, dedicated studies on human cold activated BAT combined with measurements on energy expenditure are restricted to five studies (Saito 


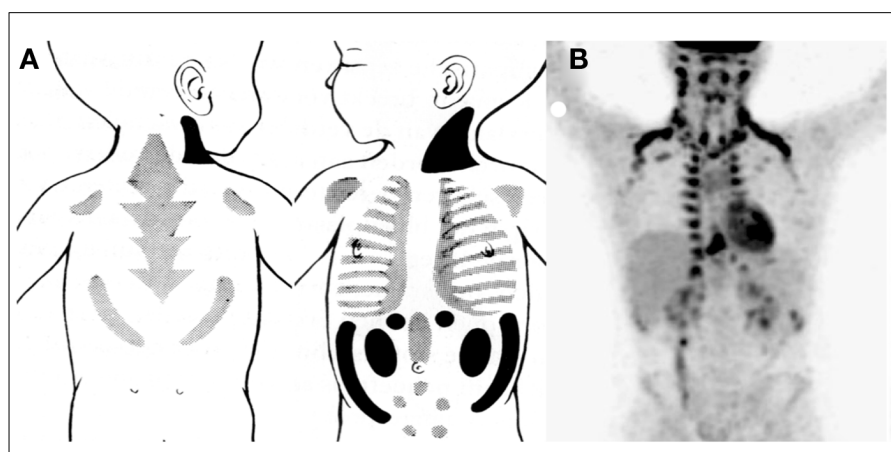

FIGURE 1 | Examples of brown adipose tissue in the newborn [(A) Merklin, 1974], 13-year-old boy [(B) Hong et al., 2011], adult male [(C) van Marken Lichtenbelt et al., 2009], and a morbid obese male [(D) Vijgen

et al., 2009; van Marken Lichtenbelt et al., 2009; Orava et al., 2011; Vijgen et al., 2011; Yoneshiro et al., 2011). Two of these studies show that subjects with BAT have higher CIT (Vijgen et al., 2011; Yoneshiro et al., 2011). Only one study shows that there is a correlation between BAT activity (i.e., FDG uptake) and NST (Yoneshiro et al., 2011). One study shows an association between BAT perfusion (by $\left[{ }^{15} \mathrm{O}\right] \mathrm{H}_{2} \mathrm{O}$ PET/CT) and energy expenditure in the cold (Orava et al., 2011). However in this study no distinction has been made between CIT and RMR. Another study shows that there is a relation between BAT activity and RMR (van Marken Lichtenbelt et al., 2009). It is disputed whether the RMR measurements (at $22^{\circ} \mathrm{C}$ ) in this study were really under thermoneutral conditions, because $28^{\circ} \mathrm{C}$ is reported to be thermoneutral (Nedergaard et al., 2011). However, the thermoneutral conditions were established in naked or very sparsely clothed humans (Erikson et al., 1956; Dauncey, 1981), while during the BAT tests the subjects wore more clothes $(0.49$ clo). Therefore, indeed RMR was measured. Higher levels of BAT could indicate higher levels of cold acclimatization, which in turn are related to elevated levels of RMR. It should be noted, however, that the issue of measurements conditions during thermoneutral conditions and during mild cold does deserve special attention (see below).

In summary, the available studies at best provide a relation between BAT FDG-activity and NST, but from these data the contribution of BAT cannot be quantified. Prudent calculations based on maximal BAT oxygen consumption in rodents combined with allometric considerations, and based on PET/CT scans reveal a contribution of activated BAT of $3-5 \%$ of BMR (Virtanen et al., 2009; van Marken Lichtenbelt and Schrauwen, 2011). These numbers are based on $50 \mathrm{~g}$ of BAT (based on FDG-PET/CT). From a physiological and practical point of view a 5\% contribution is significant. Moreover, the individual variation is high, meaning that higher contributions are likely. Based on PET/CT the amount of BAT ranges from 0 to $130 \mathrm{~g}$ (van Marken Lichtenbelt et al., 2009; Orava et al., 2011). For the calculations several assumptions were made that must be verified. For actual quantification of human BAT energy expenditure more information is needed about the actual amount of BAT, the brown fat cell density of the tissue, and the mass-specific (or cell specific) BAT energy expenditure. Moreover it is possible that BRITE cells from less distinct depots have an
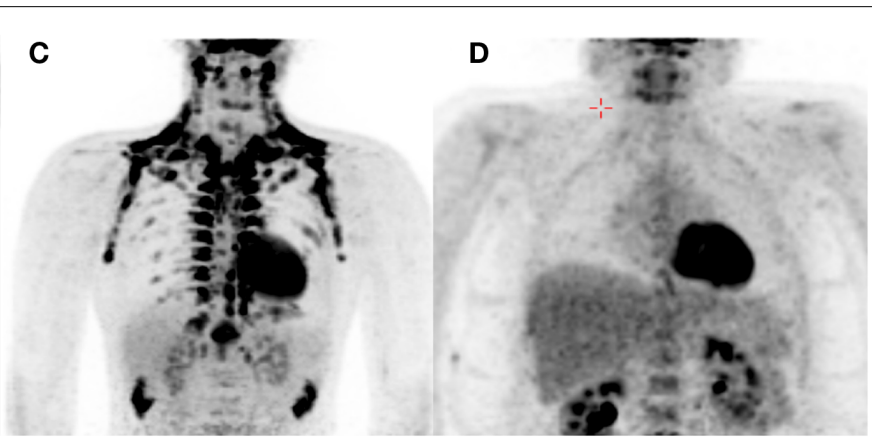

et al., 2011]. Note that the drawings of BAT in newborns are based on anatomical studies and that the scan 13-year-old boy was carried out without a specific cooling protocol.

additional contribution to NST. They have not yet been mapped in humans, because their FDG uptake is below the detection limit of PET/CT. However these cells may be abundant in many white adipose tissue, and therefore can have a significant contribution.

Another important aspect not yet studied is to what extent BAT needs to be activated to have a significant effect on energy expenditure. May be maximal activation of BAT needs uncomfortable low temperatures. It is likely that temperatures just below the thermoneutral zone do not activate BAT maximally, but are acceptable from a comfort point of view. Studies are needed to find out to what extend sub maximally activated BAT increases thermogenesis. It is likely that those conditions will be more readily accepted in our daily living environment such as offices and dwellings.

\section{DIET INDUCED THERMOGENESIS AN BAT DIET INDUCED THERMOGENESIS}

Diet induced thermogenesis can be subdivided in an obligatory part and a facultative part. Obligatory DIT encompasses the heat generated by digestion, absorption, and processing of the food. The facultative DIT is the regulated heat production used to dissipate food energy. This part is affected by for instance glucose tolerance, insulin sensitivity, body fat (distribution), and the sympathetic nervous system (SNS) activity (Valensi et al., 1998; Camastra et al., 1999). The SNS activity in its turn is elevated due to feeding (Young and Landsberg, 1977). Especially carbohydrate intake (Schwartz et al., 1999) and a very low protein diets increase the facultative thermogenesis (Stock, 1999). On the other hand the activity of the SNS is reduced in response to starvation (Young and Landsberg, 1977). The SNS-response to feeding significantly contributes to DIT (Ravussin and Swinburn, 1992).

The SNS is concerned in both the facultative part of DIT and NST. Where NST is a means of protecting the body against cold, the facultative part of DIT is a mechanism for enriching nutrient poor diets by disposing of the excess non-essential energy (Stock, 1999). Thus, facultative DIT increases as the diet becomes unbalanced (e.g., low protein content). On the other hand the increase in DIT after a high protein diet results from the high metabolic costs of metabolizing protein and is a form of obligatory thermogenesis not involving the SNS. One of the first studies on facultative DIT was on pigs showing that animals with a rather extreme low 
protein diet had a much higher DIT than those with a high protein weaning diet (Miller and Payne, 1962). Several studies followed that indicted that the SNS was involved. Stirling and Stock (1968) showed that both CIT and DIT involve SNS activation of heat production.

In humans such experiments are very rare. One study compared the variations in thermogenesis in subjects exposed to both mild cold (3 days) and overfeeding ( 3 days, 160\% of normal energy intake; Wijers et al., 2007). The changes in energy expenditure during mild cold exposure and overfeeding were significantly correlated. These results thus reveal that both overfeeding-induced and mild CIT are individual specific and may share common regulating mechanisms, confirming results from animal studies (Feldmann et al., 2009). Indeed, there was a significant correlation between fasting norepinephrine plasma concentrations and energy expenditure in both situations. Although fasting catecholamine levels may not be the best indicator, this result is in line with SNS involvement.

\section{DIT AND BAT}

It was not until the publication of Rothwel and Stock (1979) that the link between DIT and BAT was established in rodents, although this link has recently been disputed (Kozak, 2010).

Are there any indications for a relation between the food intake or diet composition and BAT activity in humans? Currently there are no dedicated studies available. From studies from Nuclear Medicine carried out to reduce BAT FDG uptake for cancer research, it is evident that the diet composition may affect FDG uptake in BAT. A high fat low carbohydrate diet reduced BAT uptake compared to a fasted condition (Williams and Kolodny, 2008). This was explained by the fact that fatty acids are used as main fuel and secondly by the Randle effect (fatty acids loading inhibits glucose metabolism). This study however, does not provide evidence for nutritional activation of BAT in humans. It does show that nutritional manipulation can affect BAT activity, in this case reduced glucose (or FDG) uptake. However, there are no elaborate studies that show that food intake can increase BAT activity.

Indirectly, there is some evidence of involvement of BAT in DIT in humans. That is, insulin, which normally is increased after eating, increases human BAT metabolism (Orava et al., 2011). Glucose uptake was measured with FDG-PET/CT, while plasma insulin concentration was elevated by using euglycemic hyperinsulinemic clamp technique $(1 \mathrm{mU} / \mathrm{kg} / \mathrm{min})$. It turned out that Insulin-stimulated glucose uptake rate in BAT was higher than in white adipose tissue, similar to skeletal muscle, but less than cold stimulated glucose uptake in BAT. This indicates that food intake, which elevates insulin levels, may activate BAT as well. Interestingly, while during cold exposure BAT both glucose uptake and blood perfusion are elevated, insulin induced glucose uptake was not accompanied with an increase in blood perfusion. Probably, the glucose is transported into the brown adipocyte without an increase in thermogenesis. If certain diets increase both glucose uptake and/or perfusion in BAT awaits investigation.

In conclusion, there is no dietary intervention study in humans available that shows a relation between food intake, dietary composition, or overfeeding and BAT activity. Such studies simply still need to be performed.

\section{BAT AND OBESITY}

Obese subjects tend to show a blunted NST under the same mild cold situation compared to lean subjects (Claessens-van Ooijen et al., 2006; Wijers et al., 2010). The reason for this can be twofold: NST is impaired in obese subjects or obese people just need a cooler environment to trigger NST. The latter can be attributed to the insulation properties of subcutaneous fat (Bar-or et al., 1969; Claessens-van Ooijen et al., 2006; Savastano et al., 2009), surface-to-volume ratio (Kurz et al., 1995), or skin vasoconstrictive reaction to cold (Valensi et al., 2000). These properties can reduce body heat loss from the skin. This in turn affects the trigger for NST. Indeed, it has been shown that the individual variation in $24 \mathrm{~h}$ NST was negatively related to changes in distal skin temperatures (van Marken Lichtenbelt et al., 2002). On the other hand, a blunted NST in the obese can also be caused by a different cold-induced autonomic responsiveness (Matsumoto et al., 1999, 2001) or to a reduced TSH and thyroid hormone response (Lean et al., 1988). From these observed differences in the mechanisms involved in heat loss and heat production, it cannot be deduced whether reduced hormonal or neural responses are a consequence of obesity or a causal factor for the risk of weight gain. Finally, there are indications of a genetic component involved in thermogenesis and BAT that come from UCP1 and beta-adrenergic receptor polymorphism studies (see van Marken Lichtenbelt and Schrauwen, 2011).

Several retrospective studies show that BAT prevalence and the amount of active BAT is lower in obese subjects (Cypess et al., 2009; Pfannenberg et al., 2010; Wang et al., 2011). However, retrospective studies generally show a lower prevalence, because these patient studies were not designed for activating BAT (Nedergaard et al., 2011; van Marken Lichtenbelt and Schrauwen, 2011). Using a standardized cold exposure protocol we showed that BAT activity was significantly negatively related to body mass index (BMI) and to percent body fat (van Marken Lichtenbelt et al., 2009). In a followup study on morbid obese subjects we extended the range of BMI and body fat percentage (Vijgen et al., 2011). In this study we used an individualized protocol and cooled the subjects to maximal non-shivering conditions. The combined results clearly confirm the negative relationship between active BAT and BMI or body fat (Figure 2). The subjects were in the age range of 18-32 years (lean to obese) and 25-51 years (morbid obese subjects). In both studies most subjects were young adults. This means that the relation with body fat is independent of age. Based on the combined data of two other studies (Saito et al., 2009; Zingaretti et al., 2009) it was postulated that the interrelationship between age and obesity may obscure the relationship between BAT and obesity (Nedergaard et al., 2011). Our results however, clearly show the relation between BAT and obesity is independent of age. This does not mean that the interrelationship does not exist. A reduced active BAT in elderly can at least partly be explained by increased adiposity with age. In other words the relation between BAT and age may be obscured by differences in body composition. Future studies should try to measure BAT in elderly with varying body compositions.

\section{BODY COMPOSITION MEASUREMENT}

Most human BAT studies use body fat (by dual X-ray absorptiometry, DXA) or BMI as an indication of obesity. Because BAT 


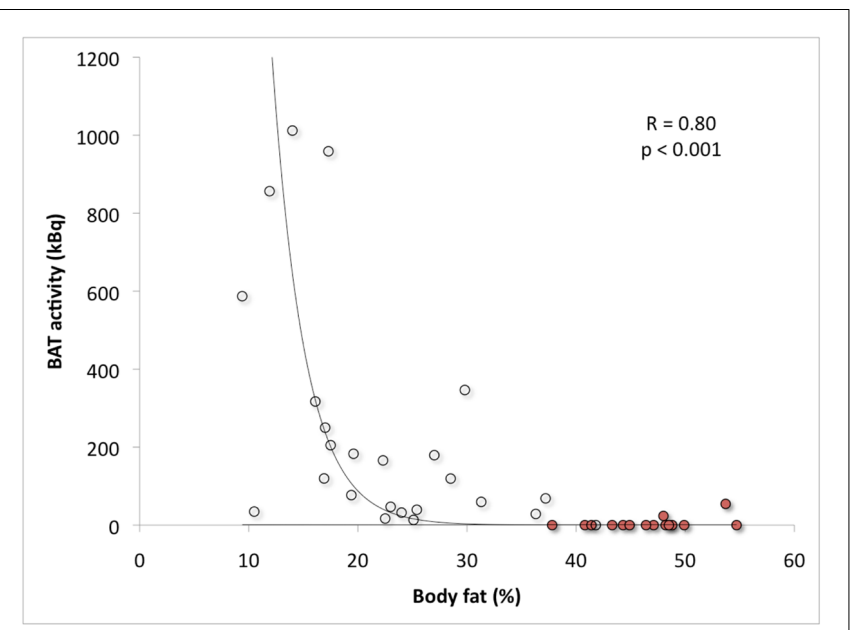

FIGURE 2 | Brown adipose tissue activity in relation to body fat percentage. The open dots indicate the study group ranging from lean to morbidly obese obese (age range: 18-32 years; van Marken Lichtenbelt et al., 2009) and the red dots indicate a second group of morbidly obese subjects (age range: $25-51$ years; Vijgen et al., 2011).

activation by cold depends on the insulation properties of the body, preferably more information about body fat distribution then DXA gives should be obtained. Especially the amount of subcutaneous body fat and skeletal muscle in the limbs is needed. DXA provides to some extend a possibility to map body fat, but with scanning techniques such as magneto resonance imaging (MRI) or CT more details on subcutaneous body fat can be determined. DXA is the most widely used technique for determining whole body fat percentage, but it is not very accurate on an individual level. It is used because of convenience, not because of accuracy. In fact DXA has a substantial error up to $6.7 \%$ compared to the gold standard (four-compartment model; Wong et al., 2002; van Marken Lichtenbelt et al., 2004; Minderico et al., 2008). This means that the DXA results are comparable to methods such as skinfold thickness and bioimpedance analyses. A serious problem is that the DXA companies do not provide details about their assumptions and calculations and comparisons of different instruments indicate a large inter-instrument variability. More attention should be given to the errors involved and that a significant part of the variation in metabolic studies potentially can be ascribed to the variation in body composition (DXA) results. Most accurate method is the three-compartment model combining underwater weighing with deuterium dilution (or the four-compartment model including a DXA bone scan; useful in subjects with low bone mineral densities). Unfortunately these techniques do not provide information about the body fat distribution. Alternatively imaging techniques such as CT and MRI are very useful because they do provide details on body fat distribution and subcutaneous fat. CT has better resolution than DXA but provides greater ionizing radiation exposure. MRI provides detailed information but needs a longer imaging time and specialized equipment for acquisition and analysis (Silver et al., 2010).

\section{METABOLIC STUDIES AND ENVIRONMENTAL TEMPERATURE}

Metabolic studies on BAT activity using (mild) cold exposure need to be carried out correctly, preferably in a standardized fashion. Both the cold and the thermal neutral conditions have to be selected carefully. Wrong environmental temperatures can result in wrong conclusion as has been shown recently with rodents that are in general raised and housed at temperatures below their thermoneutral zone. These conditions resulted in the wrong conclusions that UCP1 knock out mice fail to become obese (Feldmann et al., 2009). The mice shivered in order to keep warm. Feldmann et al. (2009) elegantly demonstrated that when these mice were kept at thermoneutrality, UCP1 ablation in itself did induce obesity.

Cold exposure experiments in humans should be carried out with the temperature conditions adjusted to the individual. This holds for both the cold situation (e.g., maximal non-shivering conditions without shivering; Vijgen et al., 2011) and for the thermoneutral condition (Kingma et al., 2011). Both conditions are important because the level of NST is calculated by the difference in energy expenditure of each condition. The importance of individual attuned environmental conditions in human metabolic studies has very often been neglected.

Many factors influence the thermoneutral zone, such as body composition (degree of obesity), fat distribution, clothing, energy expenditure, age, and gender (Kingma et al., 2011). These factors have the potential to introduce bias in study results and therefore need to be taken into consideration in studies on energy metabolism, obesity, medical conditions, thermal comfort, or vigilance. It is needed to go back to the basics of human thermoregulation. For instance, when baseline conditions are carried out at too low temperatures some NST may already occur. The NST calculated after cold exposure would then result in too low values. For more examples and the determination of the thermoneutral zone see Kingma et al. (2011).

The same applies for the experiments under mild cold conditions. The goal is to establish maximal BAT activity and NST under non-shivering conditions. During shivering much of the FDG label will be taken up by the skeletal muscle and the relation between CIT and BAT activity will be obscured by shivering thermogenesis due to competition in FDG uptake in the tissues. The few dedicated human BAT studies use a standard, more, or less fixed protocol under mild cold conditions (around $16^{\circ} \mathrm{C}$ ) sometimes with additional ice cooling of the feet. It is disputed whether ice (or cold pressor test) is an effective way of stimulating BAT, because it works systemically (Nedergaard et al., 2011). BAT, however, is normally selectively stimulated via sympathetic nerve fibers that are activated by the coldsensitive centers in the brain.

In our recent studies we cool subjects until the start of shivering, which is monitored by EMG and questionnaires (Vijgen et al., 2011). Then we raise the temperature slightly, so that the shivering just stops. In this way we want to achieve maximal NST. It is assumed that the NST level will not increase when shivering starts, although this is hard to prove. Our current trials also indicate that the rate of cooling may affect the level of NST with a lower level of NST during fast cooling due to an earlier onset of shivering. Finally, we also obtained indications that for activating 
BAT it matters which parts of the body skin are exposed to the cooling medium.

In conclusion, several studies indicate differences in BAT activity and thermogenesis between individuals and between groups (lean and obese), but for more subtle and physiological relevant differences more care should be taken in the study design and the attuning of environmental conditions.

\section{OTHER TISSUES INVOLVED - SKELETAL MUSCLE}

Theoretically other tissues and other processes than mitochondrial uncoupling (e.g., Ca-cycling, transmembrane ion leak) may be responsible for the increase in energy expenditure upon cold exposure. Skeletal muscle is potentially a significant contributor to NST as indicated in older studies using adrenalin, ephedrine, or carbohydrate induced thermogenesis (Astrup et al., 1985, 1986; Simonsen et al., 1992). An estimated contribution amounts to 35$67 \%$ of the CIT or DIT (Simonsen et al., 1992; van Baak, 2008). More recently, it is shown that human NST in response to cold exposure is accompanied by and significantly related to mitochondrial uncoupling in skeletal muscle (Wijers et al., 2008, 2011). The last study also indicates that both BAT and skeletal muscle play a role in NST with their relative contribution depending on which beta receptors are involved (beta 2 for skeletal muscle; beta 3 for BAT). More details on the involvement of skeletal muscle are given in van Marken Lichtenbelt and Schrauwen (2011).

The actual in vivo increased energy expenditure of skeletal muscle and of BAT during cold have not been studied. Moreover for a comparison about the contribution of the different tissues one relies on various techniques of which the results are not quantitatively comparable. For skeletal muscle biopsies and cell respiration measurements are used, while for BAT volume and activity the glucose tracer FDG provides the information. For a sound comparison between the contributions of each tissue, comparable techniques are needed. New techniques such as MRI, functional MRI (fMRI), or magneto resonance spectrometry (MRS) may in future be applied in both skeletal muscle and BAT (Barker and Armstrong, 2010; Hu et al., 2010). Alternatively, the implementation and development of (dynamic) PET techniques combining FDG and fatty acid tracers, tracers measuring blood perfusion (Orava et al., 2011), sympathetic innervation, thermogenesis, or oxygen consumption also are promising in this respect (Baba et al., 2007; Madar et al., 2011).

\section{REFERENCES}

Astrup, A., Bulow, J., Christensen, N. J., Madsen, J., and Quaade, F. (1986). Facultative thermogenesis induced by carbohydrate: a skeletal muscle component mediated by epinephrine. Am. J. Physiol. 250, E226-E229.

Astrup, A., Bulow, J., Madsen, J., and Christensen, N. J. (1985). Contribution of BAT and skeletal muscle to thermogenesis induced by ephedrine in man. Am. J. Physiol. 248, E507-E515.

Au-Yong, I. T., Thorn, N., Ganatra, R., Perkins, A. C., and Symonds, M. E.

\section{BAT RECRUITMENT}

Finally, in relation to obesity it is important to know whether brown fat (both BAT and BRITE) can be recruited and then used to increase energy expenditure. In the case of obesity, the question is whether obesity develops because obese people are prone to have less BAT or whether during the development of obesity BAT gradually disappears. The latter can be explained by the larger insulation of the subcutaneous fat layer and the smaller surface-to-volume ratio. Therefore obese people are less often in a situation where NST is needed compared to their lean counterparts.

In this respect it is important to study whether BAT can be recruited by cold acclimatization or dietary intervention. No intervention studies are available yet, except for the earlier mentioned study by Davis (1961) on cold acclimatization. Recent data on morbidly obese subjects show that indeed BAT can be recruited by weight loss (Vijgen et al., in review), indicating that low levels or absence of BAT is a result of obesity.

\section{CONCLUSION}

Adult humans do show NST up to $30 \%$ of BMR and BAT seems to contribute significantly. Contrary to rodent studies skeletal muscle thermogenesis may also be involved. There is a clear (negative) relation between BAT and the degree of obesity and there is an indication that weight loss can recruit BAT. However, more basic studies are needed on cold acclimatization and dietary interventions in relation to BAT activity.

More knowledge is needed about the relative presence in BAT and BRITE in humans and the actual BAT metabolic activity in comparison with other tissues. There exist several new and promising techniques that deserve more attention, such as dynamic PET/CT, the use of new PET tracers, and techniques such as fMRI and MRS should be explored. Cold exposure studies should be carried out in a more standardized fashion, taken into account the individual variation in thermoneutral zone and in ambient temperature to induce NST. For the metabolic studies on BAT related to obesity body composition methods should include fat distribution, especially the measurement of subcutaneous fat.

\section{ACKNOWLEDGMENTS}

The author acknowledges support for this study from Netherlands Science Foundation ZonMw TOP 91209037 and NL Agency EZ-EOS LT 03001. The fruitful discussions with our Thermoregulation Literature Club and the critical reading of the manuscript by Guy Vijgen are highly appreciated.

a review. Pediatr. Exerc. Sci. 22, 350-368.

Bar-or, O., Lundegren, H. M., and Buskirk, E. R. (1969). Heat tolerance of exercising obese and lean women. J. Appl. Physiol. 26, 403-409.

Camastra, S., Bonora, E., Del, S. Prato, Rett, K., Weck, M., and Ferrannini, E. (1999). Effect of obesity and insulin resistance on resting and glucose-induced thermogenesis in man. EGIR (European Group for the Study of Insulin Resistance). Int. J. Obes. Relat. Metab. Disord. 23, 1307-1313
Cannon, B., and Nedergaard, J. (2004). Brown adipose tissue: function and physiological significance. Physiol. Rev. 84, 277-359.

Celi, F., Butler, P. W., Brychta, R. J., Linderman, J. D., Alberobello, A. T., Smith, S., Courville, A. B., Lai, E. W., Costello, R., Skarulis, M., Csako, G., Remaley, A., Pacak, K., and Chen, K. Y. (2010). Minimal changes in environmental temperature result in a significant increase in energy expenditure and changes in the hormonal homeostasis in healthy adults. Eur. J. Endocrinol. 163, 863-872. 
Cinti, S. (2009). Transdifferentiation properties of adipocytes in the adipose organ. Am. J. Physiol. Endocrinol. Metab. 297, E977-E986.

Claessens-van Ooijen, A. M., Westerterp, K. R., Wouters, L., Schoffelen, P. F., van Steenhoven, A. A., and van Marken Lichtenbelt, W. D. (2006). Heat production and body temperature during cooling and rewarming in overweight and lean men. Obesity (Silver Spring) 14, 1914-1920.

Cohade, C., Osman, M., Pannu, H. K., and Wahl, R. L. (2003). Uptake in supraclavicular area fat ("USAFat"): description on 18F-FDG PET/CT. J. Nucl. Med. 44, 170-176.

Cramer, W. (1920). On glandular adipose tissue, and its relation to the endocrine organs and the vitamin problem. Br. J. Exp. Pathol. 1, 184-196.

Cypess, A. M., Lehman, S., Williams, G., Tal, I., Rodman, D., Goldfine, A. B., Kuo, F. C., Palmer, E. L., Tseng, Y. H., Doria, A., Kolodny, G. M., and Kahn, C. R. (2009). Identification and importance of brown adipose tissue in adult humans. N. Engl. J. Med. 360, 1509-1517.

Dauncey, M. J. (1981). Influence of mild cold on 24 h energy expenditure, resting metabolism and dietinduced thermogenesis. Br. J. Nutr. 45, 257-267.

Davis, T. R., Johnston, D. R., Bell, F. C., and Cremer, B. J. (1960). Regulation of shivering and non-shivering heat production during acclimation of rats. Am. J. Physiol. 198, 471-475.

Davis, T. R. A. (1961). Chamber cold acclimatization in man. J. Appl. Physiol. 16, 1011-1015.

Erikson, H., Krog, J., Andersen, K. L., and Scholander, P. F. (1956). The critical temperature in naked man. Acta Physiol. Scand. 37, 35-39.

Feldmann, H. M., Golozoubova, V., Cannon, B., and Nedergaard, J. (2009). UCP1 ablation induces obesity and abolishes diet-induced thermogenesis in mice exempt from thermal stress by living at thermoneutrality. Cell Metab. 9, 203-209.

Fruhbeck, G., Becerril, S., Sainz, N., Garrastachu, P., and Garcia-Velloso, M. J. (2009). BAT: a new target for human obesity? Trends Pharmacol. Sci. 30, 387-396.

Gilsanz, V., Chung, S. A., Jackson, H., Dorey, F. J., and Hu, H. H. (2011). Functional brown adipose tissue is related to muscle volume in children and adolescents. J. Pediatr. 158, 722-726.

Golozoubova, V., Hohtola, E., Matthias, A., Jacobsson, A., Cannon, B., and
Nedergaard, J. (2001). Only UCP1 can mediate adaptive nonshivering thermogenesis in the cold. FASEB J. 15, 2048-2050.

Hany, T. F., Gharehpapagh, E., Kamel, E. M., Buck, A., Himms-Hagen, J., and von Schulthess, G. K. (2002). Brown adipose tissue: a factor to consider in symmetrical tracer uptake in the neck and upper chest region. Eur. J. Nucl. Med. Mol. Imaging 29, 1393-1398.

Heaton, J. M. (1972). The distribution of brown adipose tissue in the human. J. Anat. 112, 35-39.

Hong, T. S., Shammas, A., Charron, M., Zukotynski, K. A., Drubach, L. A. and Lim, R. (2011). Brown adipose tissue 18F-FDG uptake in pediatric PET/CT imaging. Pediatr. Radiol. 41, 759-768.

Hu, H. H., Smith, D. L. Jr., Nayak, K. S. Goran, M. I., and Nagy, T. R. (2010). Identification of brown adipose tissue in mice with fat-water IDEALMRI. J. Magn. Reson. Imaging 31, 1195-1202.

Huttunen, P., Hirvonen, J., and Kinnula, V. (1981). The occurrence of brown adipose tissue in outdoor workers. Eur. J. Appl. Physiol. Occup. Physiol. 46, 339-345.

Karlberg, P., Moore, R. E., and Oliver, T. K. Jr. (1965). Thermogenic and cardiovascular responses of the newborn baby to noradrenaline. Acta Paediatr. Scand. 54, 225-238.

Kingma, B. R. M., Frijns, A. J. H., and van Marken Lichtenbelt, W. D. (2011). The thermoneutral zone: implications for metabolic studies. Front. Biosci. (Schol. Ed.) [Epub ahead of print].

Klingenberg, M., and Huang, S. G. (1999). Structure and function of the uncoupling protein from brown adipose tissue. Biochim. Biophys. Acta 1415, 271-296.

Kozak, L. P. (2010). Brown fat and the myth of diet-induced thermogenesis. Cell Metab. 11, 263-267.

Kurz, A., Sessler, D. I., Christensen, R., and Dechert, M. (1995). Heat balance and distribution during the core-temperature plateau in anesthetized humans. Anesthesiology 83, 491-499.

Lean, M. E., Murgatroyd, P. R., Rothnie, I., Reid, I. W., and Harvey, R. (1988). Metabolic and thyroidal responses to mild cold are abnormal in obese diabetic women. Clin. Endocrinol. (Oxf.) 28, 665-673.

Lebron, L., Chou, A. J., and Carrasquillo, J. A. (2010). Interesting image. Unilateral F-18 FDG uptake in the neck, in patients with sympathetic denervation. Clin. Nucl. Med. 35, 899-901.
Lee, P., Zhao, J. T., Swarbrick, M. M., Gracie, G., Bova, R., Greenfield, J. R., Freund, J., and Ho, K. K. (2011a). High prevalence of brown adipose tissue in adult humans. J. Clin. Endocrinol. Metab. 96, 2450-2455.

Lee, P., Swarbrick, M. M., Ting, J. Zhao, and Ho, K. K. (2011b). Inducible brown adipogenesis of supraclavicular fat in adult humans. Endocrinology 152, 3597-3602.

Madar, I., Isoda, T., Finley, P., Angle, J., and Wahl, R. (2011). 18Ffluorobenzyl triphenyl phosphonium: a noninvasive sensor of brown adipose tissue thermogenesis. J. Nucl. Med. 52, 808-814.

Matsumoto, T., Miyawaki, C., Ue, H., Kanda, T., Yoshitake, Y., and Moritani, T. (2001). Comparison of thermogenic sympathetic response to food intake between obese and nonobese young women. Obes. Res. 9, 78-85.

Matsumoto, T., Miyawaki, T., Ue, H. Kanda, T., Zenji, C., and Moritani, T. (1999). Autonomic responsiveness to acute cold exposure in obese and non-obese young women. Int J. Obes. Relat. Metab. Disord. 23 793-800.

Merklin, R. J. (1974). Growth and distribution of human fetal brown fat. Anat. Rec. 178, 637-645.

Meyer, C. W., Willershauser, M., Jastroch, M., Rourke, B. C., Fromme, T., Oelkrug, R., Heldmaier, G., and Klingenspor, M. (2011). Adaptive thermogenesis and thermal conductance in wild-type and UCP1-KO mice. Am. J. Physiol. Regul. Integr. Comp. Physiol. 299, R1396-R1406.

Miller, D. S., and Payne, P. R. (1962). Weight-maintenance and food intake. J. Nutr. 78, 225-262.

Minderico, C. S., Silva, A. M., Keller, K., Branco, T. L., Martins, S. S., Palmeira A. L., Barata, J. T., Carnero, E. A., Rocha, P. M., Teixeira, P. J., and Sardinha, L. B. (2008). Usefulness of different techniques for measuring body composition changes during weight loss in overweight and obese women. Br. J. Nutr. 99, 432-441.

Nedergaard, J., Bengtsson, T., and Cannon, B. (2007). Unexpected evidence for active brown adipose tissue in adult humans. Am. J. Physiol. Endocrinol. Metab. 293, E444-E452.

Nedergaard, J., Bengtsson, T., and Cannon, B. (2011). Three years with adult human brown adipose tissue. Ann. N. Y. Acad. Sci. 1212, E20-E36.

Nedergaard, J., Golozoubova, V., Matthias, A., Asadi, A., Jacobsson, A., and Cannon, B. (2001). UCP1: the only protein able to mediate adaptive non-shivering thermogenesis and metabolic inefficiency. Biochim. Biophys. Acta 1504, 82-106. Nicholls, D. G., and Locke, R. M. (1984). Thermogenic mechanisms in brown fat. Physiol. Rev. 64, 1-64.

Orava, J., Nuutila, P., Lidell, M. E., Oikonen, V., Noponen, T., Viljanen, T., Scheinin, M., Taittonen, M., Niemi, T., Enerback, S., and Virtanen, K. A. (2011). Different metabolic responses of human brown adipose tissue to activation by cold and insulin. Cell Metab. 14, 272-279.

Petrovic, N., Walden, T. B., Shabalina, I. G., Timmons, J. A., Cannon, B., and Nedergaard, J. (2010). Chronic peroxisome proliferator-activated receptor gamma (PPARgamma) activation of epididymally derived white adipocyte cultures reveals a population of thermogenically competent, UCP1-containing adipocytes molecularly distinct from classic brown adipocytes. J. Biol. Chem. 285, 7153-7164.

Pfannenberg, C., Werner, M. K., Ripkens, S., Stef, I., Deckert, A., Schmadl, M., Reimold, M., Haring, H. U., Claussen, C. D., and Stefan, N. (2010). Impact of age on the relationships of brown adipose tissue with sex and adiposity in humans. Diabetes 59, 1789-1793.

Ravussin, E., and Swinburn, B. A. (1992). Pathophysiology of obesity. Lancet 340, 404-408.

Rothwell, N. J., and Stock, M. J. (1979). A role for brown adipose tissue in diet-induced thermogenesis. Nature 281, 31-35.

Saito, M., Okamatsu-Ogura, Y., Matsushita, M., Watanabe, K., Yoneshiro, T., Nio-Kobayashi, J., Iwanaga, T., Miyagawa, M., Kameya, T., Nakada, K., Kawai, Y., and Tsujisaki, M. (2009). High incidence of metabolically active brown adipose tissue in healthy adult humans: effects of cold exposure and adiposity. Diabetes 58, 1526-1531.

Savastano, D. M., Gorbach, A. M., Eden, H. S., Brady, S. M., Reynolds, J. C., and Yanovski, J. A. (2009). Adiposity and human regional body temperature. Am. J. Clin. Nutr. 90, 1124-1131.

Schwartz, M. W., Baskin, D. G., Kaiyala, K. J., and Woods, S. C. (1999). Model for the regulation of energy balance and adiposity by the central nervous system. Am. J. Clin. Nutr. 69, 584-596.

Seale, P. (2010). Transcriptional control of brown adipocyte development and thermogenesis. Int. J. Obes. (Lond.) 34(Suppl. 1), S17-S22. 
Seale, P., Bjork, B., Yang, W., Kajimura, S., Chin, S., Kuang, S., Scime, A., Devarakonda, S., Conroe, H. M., Erdjument-Bromage, H., Tempst, P., Rudnicki, M. A., Beier, D. R., and Spiegelman, B. M. (2008). PRDM16 controls a brown fat/skeletal muscle switch. Nature 454, 961-967.

Silver, H. J., Welch, E. B., Avison, M. J., and Niswender, K. D. (2010). Imaging body composition in obesity and weight loss: challenges and opportunities. Diabetes Metab. Syndr. Obes. 3, 337-347.

Simonsen, L., Bulow, J., Madsen, J., and Christensen, N. J. (1992). Thermogenic response to epinephrine in the forearm and abdominal subcutaneous adipose tissue. Am. J. Physiol. 263, E850-E855.

Stirling, J. L., and Stock, M. J. (1968). Metabolic origins of thermogenesis induced by diet. Nature 220, 801-802.

Stock, M. J. (1999). Gluttony and thermogenesis revisited. Int. J. Obes. 23, 1105-1117.

Tanuma, Y., Ohata, M., Ito, T., and Yokochi, C. (1976). Possible function of human brown adipose tissue as suggested by observation on perirenal brown fats from necropsy cases of variable age groups. Arch. Histol. Jpn. 39, 117-145.

Tanuma, Y., Tamamoto, M., Ito, T., and Yokochi, C. (1975). The occurrence of brown adipose tissue in perirenal fat in Japanese. Arch. Histol. Jpn. 38, 43-70.

Tseng, Y. H., Cypess, A. M., and Kahn, C. R. (2010). Cellular bioenergetics as a target for obesity therapy. Nat. Rev. Drug Discov. 9, 465-482.

Valensi, P., Lormeau, B., Dabbech, M., Miossec, P., Paries, J., Dauchy, F., and Attali, J. R. (1998). Glucoseinduced thermogenesis, inhibition of lipid oxidation rate and autonomic dysfunction in non-diabetic obese women. Int. J. Obes. Relat. Metab. Disord. 22, 494-499.

Valensi, P., Smagghue, O., Pariès, J., Velayoudon, P., Lormeau, B., and Attali, J. R. (2000). Impairment of skin vasoconstrictive response to sympathetic activation in obese patients: influence of rheological disorders. Metab. Clin. Exp. 49, 600-606.

van Baak, M. A. (2008). Meal-induced activation of the sympathetic nervous system and its cardiovascular and thermogenic effects in man. Physiol. Behav. 94, 178-186.

van Marken Lichtenbelt, W. D., Hartgens, F., Vollaard, N. B. J., Ebbing, S., and Kuipers, H. (2004). Body composition changes in bodybuilders: a method comparison. Med. Sci. Sports Exerc. 36, 490-497.

van Marken Lichtenbelt, W. D., and Schrauwen, P. (2011). Implications of non-shivering thermogenesis for energy balance regulation in humans. Am. J. Physiol. Regul. Integr. Comp. Physiol. 301, R285-R296.

van Marken Lichtenbelt, W. D., Schrauwen, P., van De Kerckhove, S., and Westerterp-Plantenga, M. S. (2002). Individual variation in body temperature and energy expenditure in response to mild cold. Am. J. Physiol. 282, E1077-E1083.

van Marken Lichtenbelt, W. D., Vanhommerig, J. W., Smulders, N. M., Drossaerts, M. A. F. L., Kemerink, G. J., Bouvy, N. D., Schrauwen, P. and Teule, G. J. J. (2009). Coldactivated brown adipose tissue in healthy adult men. N. Engl. J. Med. 360, 1500-1508.

van Ooijen, A. M. J., van Marken Lichtenbelt, W. D., and Westerterp, K. R. (2001). Individual differences in body temperature and the relation to energy expenditure: the influence of mild cold. J. Therm. Biol. 26, 455-459.

Vijgen, G. H. E. J., Bouvy, N. D., Teule, G. J. J., Brans, B., Schrauwen, P., and van Marken Lichtenbelt, W. D. (2011). Brown adipose tissue in morbidly obese subjects. PLoS ONE 6, e17247. doi:10.1371/journal.pone.0017247

Virtanen, K. A., Lidell, M. E., Orava, J., Heglind, M., Westergren, R., Niemi, T., Taittonen, M., Laine, J., Savisto, N. J., Enerback, S., and Nuutila, P. (2009). Functional brown adipose tissue in healthy adults. N. Engl. J. Med. 360, 1518-1525.

Wang, Q., Zhang, M., Ning, G., Gu, W., Su, T., Xu, M., Li, B., and
Wang, W. (2011). Brown adipose tissue in humans is activated by elevated plasma catecholamines levels and is inversely related to central obesity. PLoS ONE 6, e21006. doi:10.1371/journal.pone.0021006

Warwick, P. M., and Busby, R. (1990). Influence of mild cold on 24 h energy expenditure in "normally" clothed adults. Br. J. Nutr. 63, 481-488.

Wijers, S. L., Saris, W., and van Marken Lichtenbelt, W. D. (2010). Cold induced adaptive thermogenesis in lean and obese. Obesity (Silver Spring) 18, 1092-1099.

Wijers, S. L. J., Saris, W. H. M., and van Marken Lichtenbelt, W. D. (2007). Individual thermogenic responses to mild cold and overfeeding are closely related. J. Clin. Endocrinol. Metab. 92, 4299-4305.

Wijers, S. L. J., Schrauwen, P., Saris, W. H. M., and van Marken Lichtenbelt, W. D. (2008). Human skeletal muscle mitochondrial uncoupling is associated with cold induced adaptive thermogenesis. PLoS ONE 3, e1777. doi:10.1371/journal.pone.0001777

Wijers, S. L. J., Schrauwen, P., van Baak, M. A., Saris, W. H. M., and van Marken Lichtenbelt, W. D. (2011). Beta-adrenergic receptor blockade does not inhibit cold induced thermogenesis in humans: possible involvement of brown adipose tissue. J. Clin. Endocrinol. Metab. 96, E598-E605.

Williams, G., and Kolodny, G. M. (2008). Method for decreasing uptake of 18 F-FDG by hypermetabolic brown adipose tissue on PET. AJR Am. J. Roentgenol. 190, 1406-1409.

Wong, W. W., Hergenroeder, A. C., Stuff, J. E., Butte, J. E., Smith, E. O., and Ellis, K. J. (2002). Evaluating body fat in girls and female adolescents: advantages and disadvantages of dual-energy X-ray absorptiometry. Am. J. Clin. Nutr. 76, 384-389.

Yeung, H. W., Grewal, R. K., Gonen, M., Schoder, H., and Larson, S. M. (2003). Patterns of (18)F-FDG uptake in adipose tissue and muscle: a potential source of false-positives for PET. J. Nucl. Med. 44, 1789-1796.
Yoneshiro, T., Aita, S., Matsushita, M., Kameya, T., Nakada, K., Kawai, Y., and Saito, M. (2011). Brown adipose tissue, whole-body energy expenditure, and thermogenesis in healthy adult men. Obesity (Silver Spring) 19, 13-16.

Young, J. B., and Landsberg, L. (1977). Stimulation of the sympathetic nervous system during sucrose feeding. Nature 269, 615-617.

Zingaretti, M. C., Crosta, F., Vitali, A., Guerrieri, M., Frontini, A., Cannon, B., Nedergaard, J., and Cinti, S. (2009). The presence of UCP1 demonstrates that metabolically active adipose tissue in the neck of adult humans truly represents brown adipose tissue. FASEB J. 23, 3113-3120.

Zukotynski, K. A., Fahey, F. H., Laffin, S., Davis, R., Treves, S. T., Grant, F. D., and Drubach, L. A. (2010). Seasonal variation in the effect of constant ambient temperature of 24 degrees $C$ in reducing FDG uptake by brown adipose tissue in children. Eur. J. Nucl. Med. Mol. Imaging 37, 1854-1860.

Conflict of Interest Statement: The author declares that the research was conducted in the absence of any commercial or financial relationships that could be construed as a potential conflict of interest.

Received: 29 July 2011; paper pending published: 17 August 2011; accepted: 29 September 2011; published online: 17 October 2011.

Citation: van Marken Lichtenbelt W (2011) Human brown fat and obesity: methodological aspects. Front. Endocrin. 2:52. doi: 10.3389/fendo.2011.00052 This article was submitted to Frontiers in Cellular Endocrinology, a specialty of Frontiers in Endocrinology.

Copyright (C) 2011 van Marken Lichtenbelt. This is an open-access article subject to a non-exclusive license between the authors and Frontiers Media SA, which permits use, distribution and reproduction in other forums, provided the original authors and source are credited and other Frontiers conditions are complied with. 